\title{
Perceived Risk: \\ Psychological Factors and Social Implications
}

Paul Slovic, Baruch Fischhoff and Sarah Lichtenstein Decision Research/A Branch of Perceptronics, Inc.

Eugene, Oregon 
Perceived Risk:

Psychological Factors and Social Implications

Paul Slovic, Baruch Fischhoff and Sarah Lichtenstein

Decision Research/A Branch of Perceptronics, Inc.

\section{Abstract}

Subjective judgments, whether by experts or lay people, are a major component in any risk assessment. If such judgments are faulty, risk management efforts are likely to be misdirected. This paper begins with an analysis of biases exhibited by lay people and experts when they make judgments about risk. Next the similarities and differences between lay and expert evaluations are examined in the context of a specific set of hazardous activities and technologies. Finally, insights from this research are applied to the problems of informing people about risk and forecasting public response towards nuclear power. 
Perceived Risk:

Psychological Factors and Social Implications

Paul Slovic, Baruch Fischhoff and Sarah Lichtenstein

Decision Research

A Branch of Perceptronics

Eugene, Oregon

People respond to the hazards they perceive.' If their perceptions are faulty, efforts at personal, public and environmental protection are likely to be misdirected. For some hazards, such as motor vehicle accidents, extensive statistical data are:available to guide perceptions. For other familiar activities, such as the consumption of alcohol and tobacco, assessment of risk requires complex epidemiological and experimental studies. Still other hazards, such as those associated with nuclear power, are sufficiently new that risk assessment must be based on complex theoretical analyses such as fault trees, rather than on direct experience.

Despite an appearance of objectivity, all forms of risk assessment include a large component: of subjective judgment. Someone, relying on educated intuition, must determine the structure of the problem, decide the consequences to be considered and select the relevant data and interpret it. Once the anayses have been performed, they must be communicated to those who actually manage hazards, including industrialists, environmentalists, regulators, legislators, and voters. If these people do not understand or believe the data they are shown, then distrust, conflict, and ineffective hazard management are likely.

This paper explores some psychological elements of the risk-assessment process. Its basic premises are that both the public and the experts are necessary participants in that process, that assessment is inherently subjective and prone to distortion due to judgmental 1imitations, and that understanding perceptions is crucial to effective decision making. 


\section{Judgmental Biases in Risk Perception}

When lay people are asked to evaluate risks, they seldom have statistical evidence on hand. In most cases, they must make inferences based on what they remember hearing or observing about the risk in question. Research has identified a number of general inferentiai rules that people use in such situations. These rules, known as heuristics, are employed to reduce difficult mental tasks to simpler ones. Although they are valid in some circumstances, in others they lead to large and persistent biases with serious implications.

\section{Availability}

One inferential strategy that has special relevance for risk perception is the availability heuristic (Tversky \& Kahneman, 1973). People using this heuristic judge an event as likely or frequent if instances of it are easy to imagine or recall. Because frequently occurring events are generally easier to imagine and recall than are rare events, availability is often an appropriate cue. However, availability is also affected by by numerous factors unrelated to frequency of occurrence. For example, a recent disaster or a vivid film could seriously bias risk judgments.

Availability bias, helps explain people's misperceptions and faulty decisions with regard to certain natural hazards. Kates (1962) observed that residents of flood plains appeared to be "prisoners of their experience," unable to conceptualize floods that have never occurred or to see the future as anything but a mirror of the recent past.

One particularly important implication of the availability heuristic is that discussing a low-probability hazard may increase its imaginability and, hence, its perceived riskiness, regardless of what the evidence indicates. For example, leaders in the field of recombinant DNA research quickly regretted ever bringing to public attention the remote risks of 
contamination by newly created organisms. Many discussions of the issue completely lost sight of the fact that the dangers were hypothetical and assumed that recombinant DNA laboratories were full of raging beasts. Ultimately, the very scientists whose concerns had initiated these discussions were vilified.

Judged frequency of lethal events. Availability bias is illustrated by several studies in which people judged the frequency of 41 causes of death (Lichtenstein et a1., 1978). In one study, these people were first told the annual death toll in the United States $(50,000)$ for one cause (motor vehicle accidents) and then asked to estimate the frequency of the other 40. Figure 1 compares the judged number of deaths per year with the number reported in public health statistics. If the frequency judgments equaled the statistical rates, a11 data points would fall on the identity line. Although more likely hazards generally evoked higher estimates, the points were scattered about a curved line that lay sometimes above and sometimes below the line of accurate judgment. In general, rare causes of death were overestimated and common causes of death were underestimated. In addition to this general bias, sizable specific biases are evident in Figure 1. For example, accidents were judged to cause as many deaths as diseases, whereas diseases actually take about 15 times as many lives. Homicides were incorrectly judged more frequent than diabetes and stomach cancer deaths. Pregnancies, births and abortions were judged to take about as many lives as diabetes, though diabetes actually causes about 80 times more deaths. In keeping with availability considerations, overestimated causes of death (relative to the curved line) tended to be dramatic and sensational (accidents, natural disasters, fires, homicides), whereas underestimated causes tended to be unspectacular events, which claim one victim at a time and are common in nonfatal form (e.g., smallpox vaccinations, stroke, diabetes, emphysema). 
Biased newspaper coverage and biased judgments. The availability heuristic highlights the vital role of experience as a determinant of perceived risk. If one's experiences are biased, one's perceptions are likely to be inaccurate. Unfortunately, much of the information to which people are exposed provides a distorted picture of the world of hazards. Following the study described above, Combs and Slovic (1979) examined the : reporting of causes of death in two newspapers on opposite coasts of the United States. Both newspapers exhibited similar biases in their coverage of life-threatening events. For example, violent, often catastrophic, events were reported, much more frequently than less dramatic causes of death having similar (or even greater) statistical frequencies. Moreover, these biases in newspaper coverage closely matched the biases in people's perceptions, discovered in our earlier studies.

It won't happen to me. Misleading experiences might also underlie another apparent judgmental bias, people's predelection to view themselves as personally immune to many hazards. Research shows that the great majority of individuals believe themselves to be better than average drivers, more likely than average to live past 80 , less likely than average to be harmed by products they use, and so on. Although such perceptions are obviously unrealistic, the risks may look very small from the perspective of each individual's experience. Consider automobile driving: despite driving too fast, tailgating, etc., poor drivers make trip after trip without mishap. This personal experience demonstrates to them their exceptional skill and safety. Moreover, their indirect experience via the news media shows that when accidents happen, they happen to others. Given such misleading experiences, people may feel quite justified in refusing to take protective actions such as wearing seat belts (Slovic et al., 1978). 
Out of sight, out of mind. In some situations, failure to appreciate the limits of "available" data may lull people into complacency. For example, we asked people to evaluate the completeness of a fault tree shawing the problems that could cause a car not to start when the ignition key was turned (Fischhoff et al., 1978). Respondents':judgments of completeness were about the same when looking at the full tree as when looking at a tree in which half of the causes of starting failure were deleted. In keeping with the availability heuristic, what was out of sight was also out of mind.

Overconfidence

Knowing with certainty: A particularly pernicious aspect of heuristics is that people typically have too much confidence in judgments based upon them. In another follow-up to the study on causes of death, people were asked to indicate the odds that they were correct in choosing the more frequent of two lethal events (Fischhoff et al., 1977). Odds of 100:1 or greater were given often (25\% of the time). However, about one out of every eight answers associated with such extreme confidence was wrong (fewer than 1 in 100 would have been wrong had the odds been appropriate). At odds of 10,000:1 people were wrong about $10 \%$ of the time. The psychological basis for this unwarranted certainty seems to be an insensitivity to the tenuousness of the assumptions upon which one's judgments are based. For example, extreme confidence in the incorrect assertion that homicides are more frequent than suicides may occur because people fail to appreciate that the greater ease of recalling instances of homicides is an imperfect básis for inference.

Hyperprecision. Overconfidence manifests itself in other ways as we11. A typical task in estimating uncertàin quantities such as failure 
rates is to set upper and lower bounds so that there is a certain fixed probability that the true value lies between them. Experiments with diverse groups of people making many different kinds of judgments have found that true values tend to lie outside of the confidence boundaries much too often. Results with $98 \%$ bounds are typical. Rather than $2 \%$ of the true values falling outside such bounds, $20-50 \%$ usually do so (Lichtenstein et al., 1977). Thus people think that they can estimate uncertain quantities with much greater precision than is actually the case. Overconfident experts. Unfortunately, once they are forced to go beyond their data and rely on judgment, experts may be as prone to overconfidence as lay people. Fischhoff etal. (1978) repeated their fault-tree study with professional automobile mechanics (averaging about 15 years of experience) and found them to be about as insensitive as lay persons to deletions from the tree. Hynes and Vanmarcke (1976) asked seven "internationally known" geotechnical engineers to predict the height of an embankment that would cause a clay foundation to fail and to specify confidence bounds around this estimate that were wide enough to have a $50 \%$ chance of enclosing the true failure height. None of the bounds specified by these individuals actually enclosed the true failure height.

Further evidence of expert overconfidence may be found in many technical risk assessments. For example, an official review of the Reactor Safety Study concluded that despite the study's careful attempt to calculate the probability of a core meltdown in a nuclear reactor, "we are certain that the error bands are understated. We cannot say by how much. Reasons for this include an inadequate data base, a poor statistical treatment [and] an inconsistent propagation of uncertainties throughout the calculation" (U.S. Nuclear Regulatory Commission, 1978, p. vi). The 1976 collapse of the Teton Dam provides another case in point. The Committee on Government 
Operations attributed this disaster to the unwarranted confidence of engineers who were absolutely certain they had solved the many serious problems that arose during construction (U.S. Government, 1976). Reconciling Divergent Opinions about Risk

Both casual observation of risk debates and systematic empirical data suggest that experts and lay people have quite different perceptions about the riskiness of various technologies. Given that they are prisoners of rather different experiences, such divergence is to be expected. One would like to believe that, as evidence accumultes and the public and the experts come to share a common experience, their perceptions would converge towards one "appropriate" view. Unfortunately, this is not likely to be the case. A great deal of research indicates that once formed, people's beliefs change very slowly, and are extraordinarily persistent in the face of contrary evidence (Nisbett \& Ross, 1980). Initial impressions tend to structure the way that subsequent evidence is interpreted. New evidence appears reliable and informative if it is consistent with one's initial beliefs, whereas contrary evidence is dismissed as unreliable, erroneous, or unrepresentative. Characterizing Perceived Risk

In order to aid hazard management, a theory of perceived risk must explain people's extreme aversion to some hazards, their indifference to others, and the discrepancies between these reactions and experts' recommendations. Why, for example, do some communities react vigorously , against locating a liquid natural gas terminal in their vicinity despite the assurances of experts that it is safe? Why, on the other hand, do many communities situated on earthquake faults or below great dams show little concern for experts' warnings? Over the past few years we have been attempting to answer such questions as these by examining the opinions 
people express when they are asked, in a variety of ways, to characterize and evaluate hazardous activities and technologies (Slovic, Fischhoff \& Lichtenstein, $1979,1980 a ;$ Slovic, Lichtenstein \& Fischhoff; 1979)... This descriptive research aims (a) to develop a taxonomy of risk characteristics that can be used to understand and predict societal responses to hazards and (b) to develop methods for assessing public opinions about risk in a way that could be useful for policy decisions.

Quantifying Perceived Risk

In one study, we asked four different groups of people to judge 30 hazardous activities, substances and technologies according to the "present risk of death from each (across U.S. society as a whole)." Three groups were from Eugene, Oregon; they included 69 college students, 76 members of the League of Women Voters (LOWV), and 47 business and professional members of the "Active Club." The fourth group was composed. of $15^{\circ}$ experts in risk assessment.

Table 1 rank orders the mean risk judgments for the four groups. There were many similarities between the three groups of lay people. For example, each group believed that motorcycles, motor vehicles and handguns were highly risky, while vaccinations, home appliances, power mowers, and football posed relatively little risk. However, there-were strong differences as we11. Active Club members viewed pesticides as much less risky than did the other groups. Nuclear power was rated as highest in risk by the LOWV and student groups, but only eighth by the Active Club. The students viewed contraceptives as riskier and mountain climbing as safer than did the other lay groups. Experts' judgments of risk differed markedly from the judgments of lay people. The experts viewed electric power, surgery, swimming and $X$ rays as more risky than did the other groups and they judged 
nuclear power, police work and mountain climbing to be much less risky.

Insert Table 1 about here

What Determines Risk Perception?

What did people mean, in this study, when they said that a particular technology was quite risky? A series of additional studies was addressed to this question.

Perceived risk compared to frequency of death. When people judge risk, are they simply estimating frequency of death? To answer this question, we compared the risk judgments with technical estimates of the annual number of deaths for these hazards. The experts' judgments of risk were so closely related to the statistical (or calculated) frequencies that it seemed reasonable to conclude that they had good knowledge of the technical estimates and viewed "risk" as synonymous with these estimates. The risk judgments of lay people were, however, only moderately related to the annual. death rates, raising the possibility that'risk means something different to them.

Lay fatality estimates. Perhaps lay people base their risk judgments on subjective fatality estimates which are inaccurate. To test this hypothesis, we asked additional groups of students and LOWV members to estimate how many people were likely to die in the U.S. in the next year (if the next year was an average year) as a consequence of these 30 hazardous activities. If lay people equate risk with annual fatalities, . their subjective fatality estimates, no matter how inaccurate, should resemble their risk judgments. We found, however, only a modest agreement between these two sets of judgments. Lay people's risk perceptions were, in fact, no more closely related to their own fatality estimates than they were to the technical estimates. Apparently, lay people incorporate other considerations besides annual fatalities into their concept of risk. 
Disaster potential. One clue to these other considerations was the fact that the LOWV members and students judged nuclear power as highest in risk and lowest in annual. fatalities. One possible explanation is that they considered nuclear power to be a high risk technology because of its potential for disaster. Therefore, we asked these same respondents to indicate for each hazard, "how many times more deaths would occur if next year were particularly disastrous rather than average." For most hazards these multipliers were quite sma11, indicating that people saw little potential for disaster. The striking exception was nuclear power. Applying each person's disaster multiplier to their estimated fatalities for an average year, we found that almost $40 \%$ of the respondents expected more than 10,000 fatalities from nuclear power if next year were a disastrous year. More than $25 \%$ expected 100,000 or more fatalities.

Disaster potential seems to explain the discrepancy between the perceived risk and the annual fatality estimates for nuclear power. Yet, because disaster was judged significant for only a few of the hazards, it provided only a partial explanation of the perceived-risk data.

Risk Characteristics. Our search for additional knowledge about risk perception led us to ask experts, students, LOWV members and Active Club members to rate the 30 items on nine characteristics that had been hypothesized as relevant to individual and societal reactions to hazards. These characteristics included the degree to which an activity's risks were voluntary, controllable, known to science, known to those exposed, familiar, dread, certain to be fatal, catastrophic, and immediately manifested.

Mean ratings were quite similar for all four groups. Particularly interesting was the characterization of nuclear power, which had the dubious 
distinction of scoring at or near the extreme on all of the undesirable characteristics. Its risks were seen as involuntary, delayed, unknown, uncontrollable, unfamiliar, catastrophic, dread and fatal. This contrasted sharply with the characterizations of non-nuclear electric power and another radiation technology, $\mathrm{X}$ rays. Electric power and $\mathrm{X}$ rays were both judged more voluntary, less certain to be fatal, less catastrophic, less dreaded, more familiar, and less risky than nuclear power.

Across all 30 hazards, ratings of dread and of the likelihood of a mishap being fatal were closely related to lay judgments of risk. In fact, the risk judgments of the LOWV and student groups could be predicted almost perfectly from ratings of dread and lethality and the subjective fatality estimates for normal and disastrous years. Experts' judgments of risk were not related to any of the nine risk characteristics.

Many pairs of risk characteristics tended to be correlated with each other across the 30 activities and technologies. For example, risks faced voluntarily were typically judged well known and controllable. These interrelations were sufficiently high to suggest that all the ratings could be explained in terms of a few basic dimensions of risk. In order to identify such dimensions, we conducted a factor analysis of the correlations from each group (principal components analysis with varimax rotation to simple structure). We found that the nine characteristics could be represented by two underlying factors which appeared to be the same for each group. Figure 2 illustrates the factor scores for each hazard within the common space. Hazards at the high end of the vertical dimension or factor (e.g., food coloring; pesticides) tended to be new, unknown, involuntary, and delayed in their effects. Hazards at the other extreme of this factor (e.g., mountain climbing; swimming) had the opposite characteristics. High (right-hand) scores on the horizontal factor (e.g., 
nuclear power; commercial aviation) were associated with events whose consequences were seen as certain to be fatal, often for large numbers of people, should something go wrong. Hazards low on this factor (e.g., power mowers; footba11) were seen as causing injuries rather than fatalities, to single individuals. We have labeled the vertical factor as "Unknown Risk" and the horizontal factor as "Dread Risk." In sum, even though the four groups had somewhat different perceptions of the riskiness of the various hazards (Table 1), they tended to characterize these hazards similarly.

Insert Figure 2 about here An Extended Study of Risk Perception.

In the study reported above, diverse groups of people characterized risks in the same way. But the generalizability of the factors that emerged is limited to the particular hazards and characteristics studied. Therefore, our recent work has examined a broader set of hazards (90 instead of 30) and risk characteristics (18 instead of 9), using data collected from college students. The 18 risk characteristics included eight from the earlier study, plus additional characteristics selected to represent other concerns thought to be important. These included the number of people exposed to the hazard, the degree to which the risks pose a threat to you (the rater) personally, threat to future generations, and threat of global catastrophe. We also asked about the degree to which the activity's benefits are equitably distributed to those who bear the risks, the observability of the damage producing processes, the degree to which the risks are increasing and the ease of reducing the risks.

Each of the 90 hazards was rated on overall riskiness and judged on all 18 characteristics of risk. In general, the risks from most of these activities were judged to be increasing, not easily reduced, and better known to science than to those people exposed to them. 
As in the earlier studies, many pairs of risk characteristics were highly correlated with each other. Factor analysis showed that the 18 characteristics could be represented well by three factors, the first two of which resembled the two factors that emerged from the earlier studies. Factor 1 was associated with lack of control, fatal consequences, high, catastrophic potential, reactions of dread, inequitable distribution of risks and benefits (including transfer of risks to future generations), and the belief that the risks are increasing and not easily reducable. Factor 1 thus seems to correspond closely to the factor labeled Dread Risk in the earlier study. Factor 2 was associated with risks that are unknown, unobservable, new, and delayed in their manifestation. It thus corresponded closely to Factor 1 (Unknown Risk) of the earlier study. Factor 3 was primarily determined by the number of people exposed and the rater's personal exposure.

Scores for the individual items on Factors 1 and 2 are plotted in Figure 3. The hazards at the extremes on each dimension give support to the factor names, which were initialiy determined from examination of the set of characteristics defining each factor. Items at the high end of Factor 1 (nerve gas, nuclear power accidents, nuclear weapons, terrorism, warfare and crime) are all highly dreaded, in contrast to the items at the opposite end (home appliances, bicycles, christmas tree lights, hair dyes). The locations of items on the vertical axis correspond to the degree to which their risks are perceived as known, familiar, and observable. Hazards falling at the high exposure end of factor 3 (societal and personal exposure) were motor vehicle accidents, caffeine, alcoholic beverages, smoking, food preservatives, herbicides and pesticides. Hazards falling at the low end on this factor included lasers, solar electricity, space exploration, laetrile, scuba diving, and open-heart surgery. 
Insert Figure 3 about here

Our most recent study has examined 81 hazardous activities, including many more chemicals (e.g., 2,4,5-T, hexachlorophene, polyvinyl chloride) than were included in previous studies and numerous hazards whose risks were disaggregated (e.g., motor vehicle risks were partitioned into four separate items treating (a) accidents to vehicle occupants, pedestrians and cyclists; (b) auto racing; (c) carbon monoxide exhaust; and (d) airborne lead). Factor analysis, based on ratings of these hazards on the 18 risk characteristics, resulted in three factors almost identical to those of the previous study.

We have found that lay people's risk perceptions and attitudes are closely related to the position of a hazard within the factor space. Most important is Dread Risk. The higher an activity's score on this factor (a) the higher its perceived risk; (b) the more people want its risks reduced; and (c) the more they want to see strict regulation employed to achieve the desired reduction in risk (see Figure 4). The perceptions of experts, however, appear much less closely: related to the factor space.

\section{Insert Figure 4 about here}

Social Implications

In this section, we shall briefly describe two applied problems to which we believe this basic research is relevant. One is the challenge of informing or educating people about risk. The second is the problem of understanding and forecasting public response towards new technologies, as illustrated by the case of nuclear power. Our coverage here will be brief. Further details about these two applications can be found in Slovic, Lichtenstein \& Fischhoff (1979) and Slovic et al. (1980b). Informing People About Risk

One dramatic change in people's outlook on life in recent years is their growing awareness of the risks they encounter in daily experience. 
The consequence of this awareness has been increased pressure on the designers and regulators of hazardous enterprises to inform people about the risks they face (see Figure 5). For example:

1. The Food and Drug Administration (FDA) is mandating patient information inserts for an increased number of prescription drugs.

2. The Department of Housing and Urban Development now requires the sellers of homes built before 1950 to inform buyers about the presence of lead-based paints.

3. The White House has directed the Secretary of Health, Eduation, and Welfare to develop a public information program on the health effects of radiation exposure.

Insert Figure 5 about here

Despite good intentions, creating effective informational programs may be quite difficult. Doing an adequate job means finding cogent ways of presenting complex, technical material that is clouded by uncertainty and may be distorted by the listeners' preconceptions (and perhaps misconceptions) about the hazard and its consequences. For; as we have seen above, misleading personal experiences may sometimes promote a false sense of security, whereas in other circumstances, mere discussion of possible adverse consequences may enhance their apparent threat. Moreover, research has also demonstrated that people's beliefs change slowly and show extraordinary persistence in the face of contrary evidence. What follows is a brief overview of some additional problems that information programs must confront.

Presentation format is important. Subtle changes in the way that risks are expressed can have a major impact on perceptions. For example, Slovic et a1. (1978) argued that motorists' reluctance to wear seat belts might be due to the extremely small probability of incurring a fatal accident 
on a. single automobile trip. Since a fatal accident occurs only about once in every 3.5 million person-trips and a disabling injury only once in every 100,000 person-trips, refusing to buckle one's seat belt may seem quite reasonable. It looks less reasonable, however, if one adopts a multiple-trip perspective and considers the substantial probability of an accident on some trip. Over 50 years of driving (about 40,000 trips), the probability of being killed rises to .01 and the probability of experiencing at least one disabling injury is .33 . We found that people asked to consider this 1ifetime perspective responded more favorably toward the use of seat belts (and air bags) than did people asked to consider a trip-by-trip perspective.

Numerous other format effects have been documented in the literature on risk assessment. For example, merely fusing or splitting branches in a fault tree (without adding or substracting any information) affects people's perceptions; a given category of problems tends to be viewed as contributing more to failures when split into two branches than when presented as one branch. The same risk options, described in terms of lives saved, may be evaluated much differently than when framed in terms of lives 1ost. Details of these and other effects are given in Tversky and Kahneman (in press) and Slovic et al. (1980b).

The fact that subtle differences in how risks are presented can have marked effects on perceptions and actions suggests that those responsible for information programs have considerable ability to manipulate perceptions. Moreover, since these effects are not widely known, people may inadvertently be manipulating their own perceptions by casual decisions they make about how to organize their knowledge.

Cross-hazard comparisons may be misleading. One common approach to deepening people's perspectives is presenting quantified risk estimates for a variety of hazards. These presentations typically involve elaborate 
tables and even "catalogs of risks" in which diverse indices of death or disability are displayed for a broad spectrum of life's hazards. Some of these provide extensive data on risks per hour of exposure showing, for example, that an hour of riding a motorcycle is as risky as an hour of being 75 years old. One analyst developed lists of activities, each of which is estimated to increase one's chances of death (in any year) by one in one million. Other analysts have ranked hazards in terms of their expected reduction in life expectancy. Those who compile such data typically assume that they will be useful for decision making.

Research on perceived risk implies that comparisons such as these will not, by themselves, be adequate guides to personal or public decision policies. Risk perceptions and attitudes appear to be determined not only by accident probabilities, annual mortality rates or the mean losses of life expectancy, but also by numerous other characteristics of hazards such as uncertainty, controllability, catastrophic potential, equity and threat to future generations. Within the perceptual space defined by these and other characteristics, each hazard is unique. To many persons, statements such as "the annual risk from living near a nuclear power plant is equivalent to the risk of riding an extra three miles in an automóbile" appear ludicrous because they fail to give adequate consideration to the important differences in the nature of the risks from these two technologies.

Conclusions. The development of programs to inform patients, workers and consumers about risk is an admirable goal. However, it is important to recognize the difficulties confronting such programs. There is need for extensive empirical research on the problems of communicating information about risk. Since every decision about the content and format of an information statement is likely to influence perception and behavior (and 
ultimately product viability, jobs, electricity costs, compliance with medical treatments and other high-stakes consequences), extreme care must be taken to select knowledgeable and trustworthy designers and program coordinators. Finally, it is important to recognize that informing people, whether by warning labels, package inserts, or extensive media presentations, is but part of the larger problem of helping them cope with the risks and uncertainties of modern life. We believe that much of the responsibility lies with the schools, whose curricula should include material designed to teach people that the world in which they live is probabilistic, not deterministic, and to help them learn judgment and decision strategies for dealing with that world. These strategies are as necessary for navigating in a world of uncertain information as geometry and trigonometry are to navigating among physical objects.

Forecasting Public Response: The Case of Nuclear Power

Research on risk perception can help hazard managers and policy makers understand public attitudes and forecast future acceptance or rejection of new technologies. A case in point is nuclear power, whose isolated position in the perceptual space reflects our respondents' view that its risks are unknown, dread, uncontrollable, inequitable, catastrophic and likely to affect future generations. Once such concerns are identified, one can ask how likely they are to change over time in response to education, a good safety record, or an accident.

Basic perceptions. Studies of people opposed to nuclear power show that they judge its benefits as quite low and its risks as unacceptably great (Slovic, Lichtenstein \& Fischhoff, 1979). On the benefit side, opponents do not see nuclear power as a vital link in meeting basic energy needs; rather many view it as a supplement to other sources of energy 
which are themselves adequate. On the risk side, nuclear power evokes extreme feelings of dread.

Though a number of commentators have speculated that people's strong fears of nuclear power stem from a belief that death from radiation is somehow more horrible than death from other causes, our studies indicate that, instead, their fears appear to derive from concern over how many deaths are likely. Many people's mental images of a nuclear accident include the spectre of hundreds of thousands, even millions, of immediate deaths, accompanied by incalculable and irreversible damage to the environment. These images bear little resemblance to the views of industry officials' (and most technical experts), who expect redundant safety and containment systems to prevent almost all reactor accidents and limit the damage of those that do occur. Industry proponents have tended to attribute this perception gap to public ignorance and irrationality.

We question this attribution and we doubt that its proposed remedy, education, will easily succeed. For although people's fears may be exaggerated, they are not divorced from reality. On the technical side,. the low probability of catastrophic nuclear mishaps makes demonstration of their improbability difficult from a statistical standpoint. Furthermore, people are aware that many of the "facts" of nuclear risks are in dispute and that experts have been wrong in the past, as when they irridiated enlarged tonsils or permitted observers to witness A-bomb tests at close range. On the psychological side, public concerns are triggered by reliance on memorability and imaginability (the availability heuristic). The risks of nuclear power would seem to be a prime candidate for availability bias because of the extensive media coverage they receive and their association with the vivid, imaginable dangers of nuclear war. 
One disturbing possibility is that objective discussions of nuclear safety may increase the imaginability of improbable mishaps, causing them, by the availability heuristic, to seem more likely. Consider an engineer arguing the safety of nuclear power by pointing out the improbability of the various ways radioactivity could be accidentally released. Rather than reassuring the audience, the presentation might lead them to think, "I didn't realize there were that many things that could go wrong."

Whereas availability bias may contribute to the perception gap between pronuclear experts and their lay opponents, it does not point unambiguously to one side or the other as having the most accurate appraisal of the risks from nuclear power. Although reliance on imaginability, by blurring the distinction between what is remotely possible and what is probable, is capable of enhancing public fears, inability to imagine all the possible ways that systems could fail might produce a false sense of security among technical experts. Insofar as the actual risks may never be known with great precision and the interpretation of new information is strongly influenced by one's prior beliefs, the perception gap may be with us for a long time. Thus, Three Mile Island "proved" the possibility of a catastrophic meltdown to some, whereas to others, it demonstrated the reliability of the multiple containment systems.

A Nuclear Future?

Are the strong fears and determined opposition to nuclear power 1ikely to persist? Will nuclear power ever gain widespread public acceptance? Although answers to these questions are by no means clear, public response to $\mathrm{X}$ rays provides some clues. The almost universal acceptance of $\mathrm{X}$ rays shows that a radiation technology can be tolerated if its use is familiar, its benefits clear, and its practitioners trusted. In the case of nuclear 
power, the path to respectability exemplified by $\mathrm{X}$ rays will have to be accompanied by an incontrovertible safety record. Research indicates that accidents occurring with unknown and potentially catastrophic technologies will be seen as signals that portend loss of control and indicate further, and possibly severe, losses (Slovic et a1., 1980a). Thus even "small" nuclear power accidents will likely have immense consequences for the industry and for society.

A quicker path to acceptance, and one that may provide the primary hope for the industry, could be forged by a severe energy shortage. Society has shown itself willing to accept increased risks in exchange for increased benefits. Brownouts, blackouts, or rationing of electricity would likely enhance the perceived need for nuclear power and increase public tolerance of its risks. Such crisis-induced acceptance of nuclear power may, however, produce anxiety, stress and conflict in a population forced to tolerate what it perceives as great risk because of its addiction to the benefits of electricity.

\section{Conclusion}

The study of human cognitive processes indicates that making intelligent decisions about risky activities is a very difficult task. It also raises a number of critical questions: Can society rise above the limitations of individual minds? Are new technologies forcing us to make decisions that we cannot make we11 (or successfuliy)? Should we take smaller steps in our technological development, so that we can recover from the inevitable mistakes? What kind of political institutions are needed to preserve democratic freedoms and insure public participation for problems involving technical complexity, catastrophic risks, and great uncertainty? If public debates and communications from experts do little to allay fears and, indeed, may exacerbate them, how should we structure 
public participation? What role can education play in helping society understand and cope with risk?

Although the study of individual human minds is a rather narrow starting point for examining societal risk decisions, it appears to lead quickly to important issues that need to be addressed by the entire community of scientists, policy makers, and citizens.

\section{Acknowledgement}

This work was supported by the Technology, Assessment and Risk Analysis Program of the National Science Foundation under $n$

Grant PRA79-11934 to Clark University under subcontract to Perceptronics, Inc. Any opinions, findings and conclusions expressed in this publication are those of the authors and do not necessarily reflect the views of the National Science Foundation. We are grateful to Heldref Publications, Inc. for permission to reprint material appearing in Environment, 1979, 21(3), 14-20, 36-39 and to Plenum Press for permission to reprint material from R. Schwing and W. A. Albers, Jr. (Eds.), Societal risk assessment: How safe is safe enough? $1980,181-214$. 


\section{References}

Combs, B. \& Slovic, P., 1979, Newspaper coverage of causes of death. Journalism Quarter1y, 56: , 837-843:849.

Fischhoff, B., Slovic, P. \& Lichtenstein, S., 1977, Knowing with certainty: The appropriateness of extreme confidence. Journal of Experimental Psychology: Human Perception and Performance, $\underline{3}, 552-564$.

Fischhoff, B., Slovic, P. \& Lichtenstein, S., 1978, Fault trees: Sensitivity of estimated failure probabilities to problem representation. Journal of Experimental Psychology: Human Perception and Performance, 4, 330-344.

Hynes, M. \& Vanmarcke, E., 1976, Reliability of embankment performance predictions. Proceedings of the ASCE Engineering Mechanics Division Speciality Conference. Waterloo, Ontario, Canada: University of Water1oo Press.

Kates, R. W., 1962, Hazard and choice perception in flood plain management. Chicago: University of Chicago, Department of Geography, Research Paper No. 78 .

Lichtenstein, S., Fischhoff, B. \& Phillips, L. D., 1977, Calibration of probabilities: The state of the art. In H. Jungermann \& G. deZeeuw (Eds.), Decision making and change in human affairs. Amsterdam: D. Reidel.

Lichtenstein, S., Slovic, P., Fischhoff, B., Layman, M. \& Combs, B. 1978, Judged frequency of lethal events. Journal of Experimental Psychology: Human Learning and Memory, 4, 551-578.

Nisbett, R. \& Ross, L., 1980, Human inference. Englewood Cliffs, N.J.: Prentice-Hall.

Slovic, P., Fischhoff, B. \& Lichtenstein, S., 1978, Accident probabilities and seat belt usage: A psychological perspective. Accident Analysis and Prevention, 10, 281-285. 
Slovic, P., Fischhoff, B. \& Lichtenstein, S. 1979, Ratings the risks. Environment, 21(3), 14-20, 36-39.

Slovic, P., Fischhoff, B. \& Lichtenstein, S. 1980a, Perceived risk. In R. Schwing \& W. A. Albers Jr. (Eds.), Societal risk assessment: How safe is safe enough? New York: Plenum, 181-214.

Slovic, P., Fischhoff, B. \& Lichtenstein, S. 1980b, Informing people about risk: In I. Morris, M. Mazis \& I. Barofsky (Eds.), Product labeling and health risks. Cold Spring Harbor, N. Y.: The Banbury Center.

Slovic, P., Lichtenstein, S. \& Fischhoff, B. 1979, Images of disaster: Perception. and acceptance of risks from nuclear power. In G. T. Goodman \& W. D. Rowe (Eds.), Energy risk management. Londion: Academic Press, 223-245.

Tversky, A. \& Kahneman, D. 1973, Availability: A heuristic for judging frequency and probability. Cognitive Psychology, 4, 207-232.

Tversky, A. \& Kahneman, D., in press. The framing of decisions and the rationality of choice. Science.

U. S. Government. 1976, Teton Dam disaster. Committee on Governement Operations: Washington, D. C.

U. S. Nuclear Regulatory Commission. 1978, Risk assessment review group report to the U. S. Nuclear Regulatory Commission, NUREG/CR-0400, Washington, D. C.: The Commission. 
Table 1

ORDERING OF PERCEIVED RISK FOR 30 ACTIVITIES AND TECHNOLOGIES ${ }^{a}$

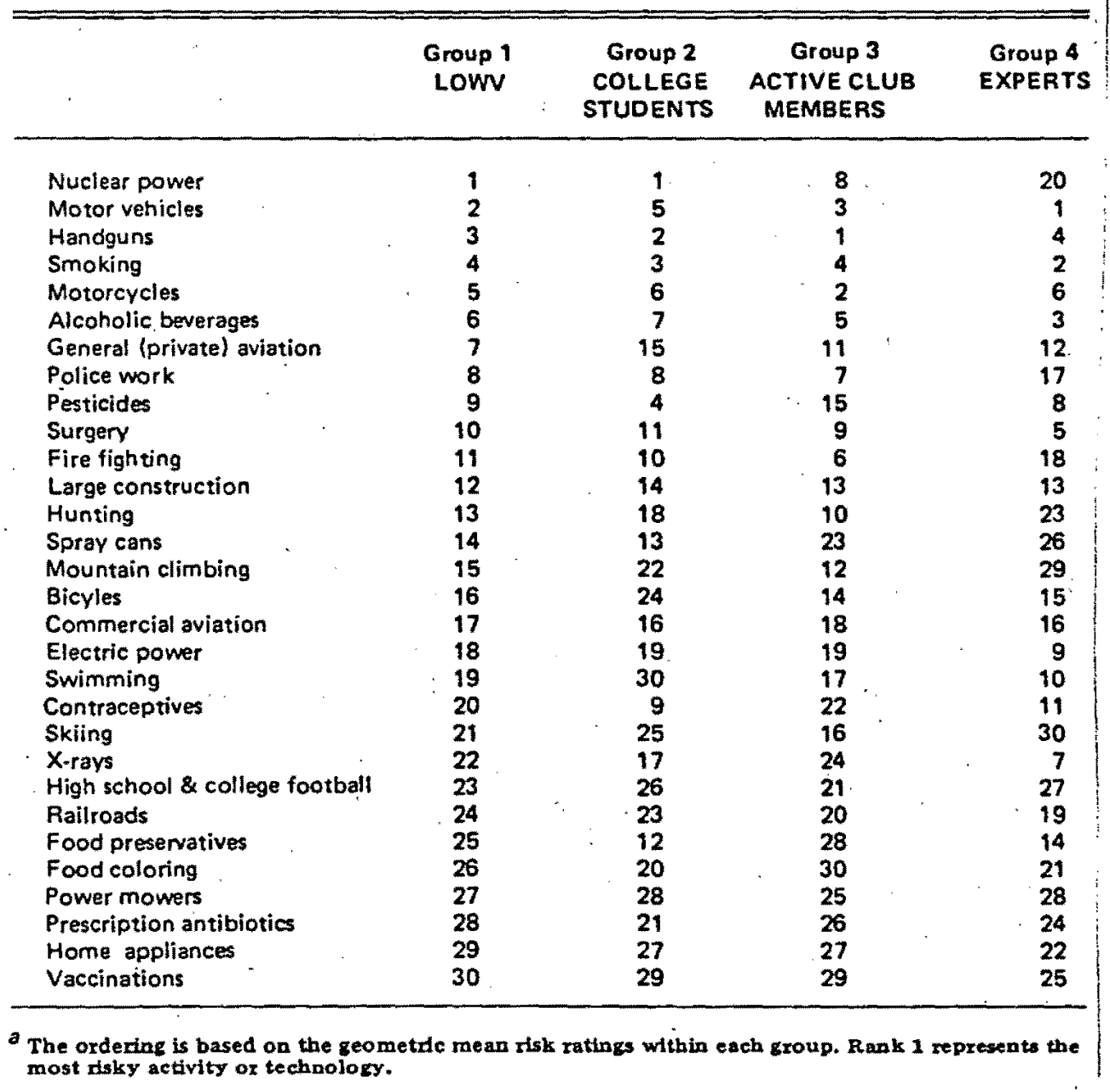




\section{Figure Captions}

1. Relationship between judged frequency and the actual number of deaths per year for 41 causes of death. Source: Lichtenstein et al. (1978).

2. Location of 30 hazards within the two-factor space obtained from LOWV, student, Active Club and expert groups. Connected lines join or enclose the loci of four group points for each hazard. Open circles represent data from the expert group. Unattached points represent groups that fall within the triangle created by the other three groups.

3. Hazard locations on Factors 1 and 2 of the three-dimensional structure derived from the interrelationships among 18 risk characteristics. Factor 3 (not shown) reflects the number of people exposed to the hazard and the degree of one's personal exposure. Source: S1ovic et a1. (1980a).

4. Attitudes towards regulation of the hazards shown in Figure 3. The larger the dot, the greater the desire for strict regulation to reduce risk.

5. Drawing by S. Harris; (c) 1979 . The New Yorker Magazine, Inc. 


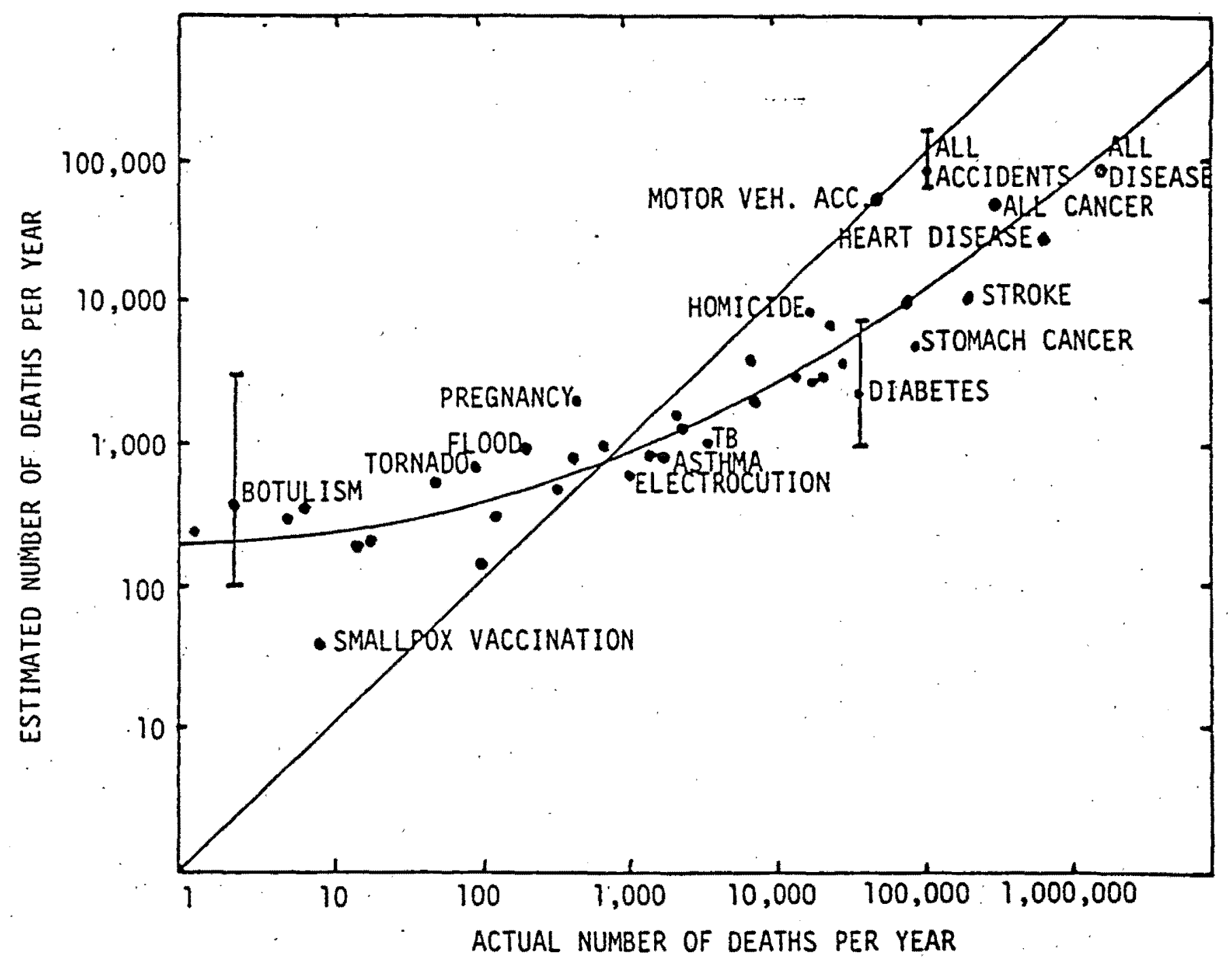

Figure 1. Relationship between judged frequency and the actual number of deaths per year for 41 causes of death.

Source: Slovic, Fischhoff \& Lichtenstein, 1979. 


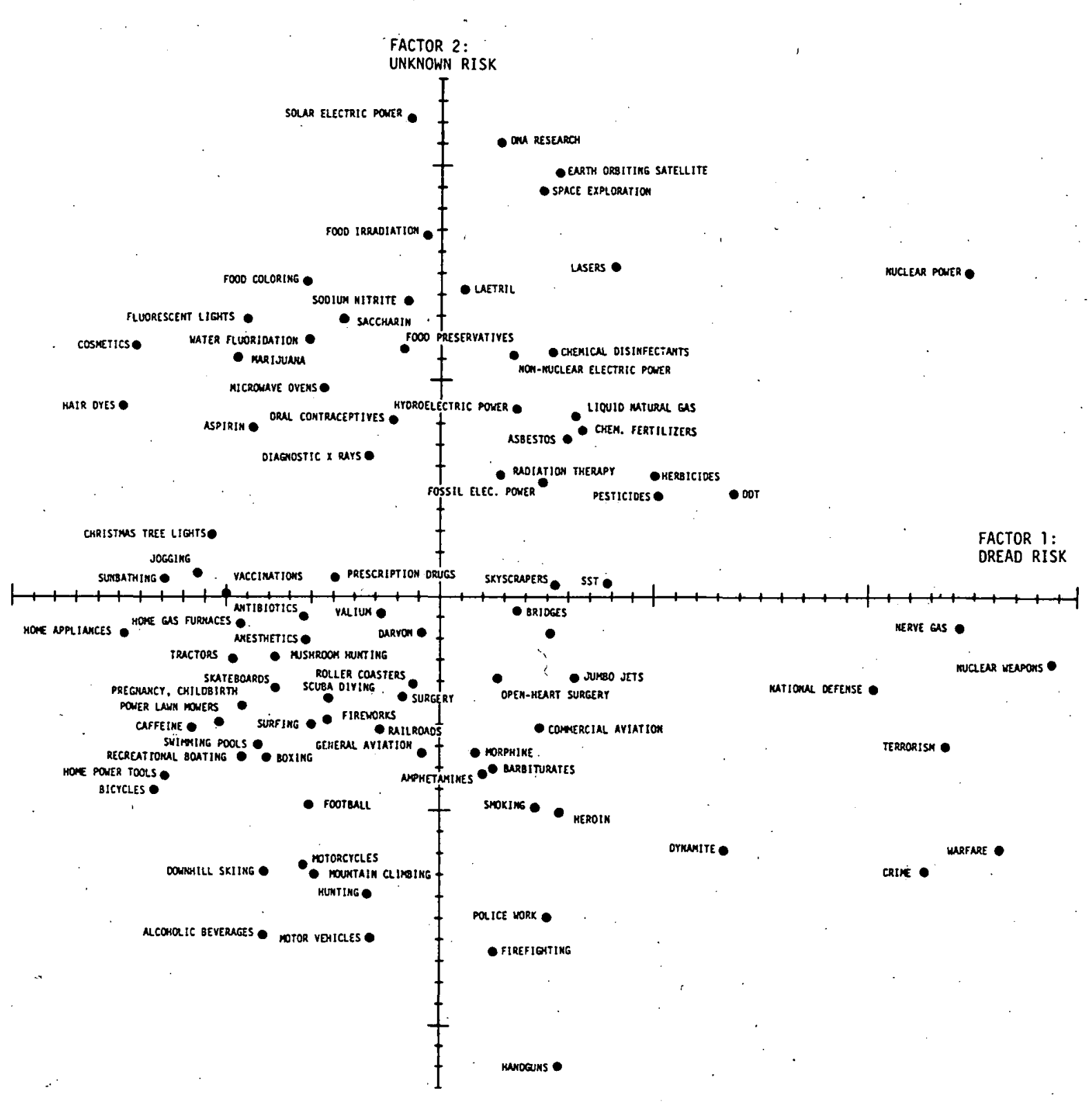

Figure 3. Hazard locations on Factors 1 and 2 of the three-dimensional structure derived from the interrelationships among 18 risk characteristics. Factor 3 (not shown) reflects the number of people exposed to the hazard and the degree of one's personal exposure. Source: Slovic et al., 1980a. 


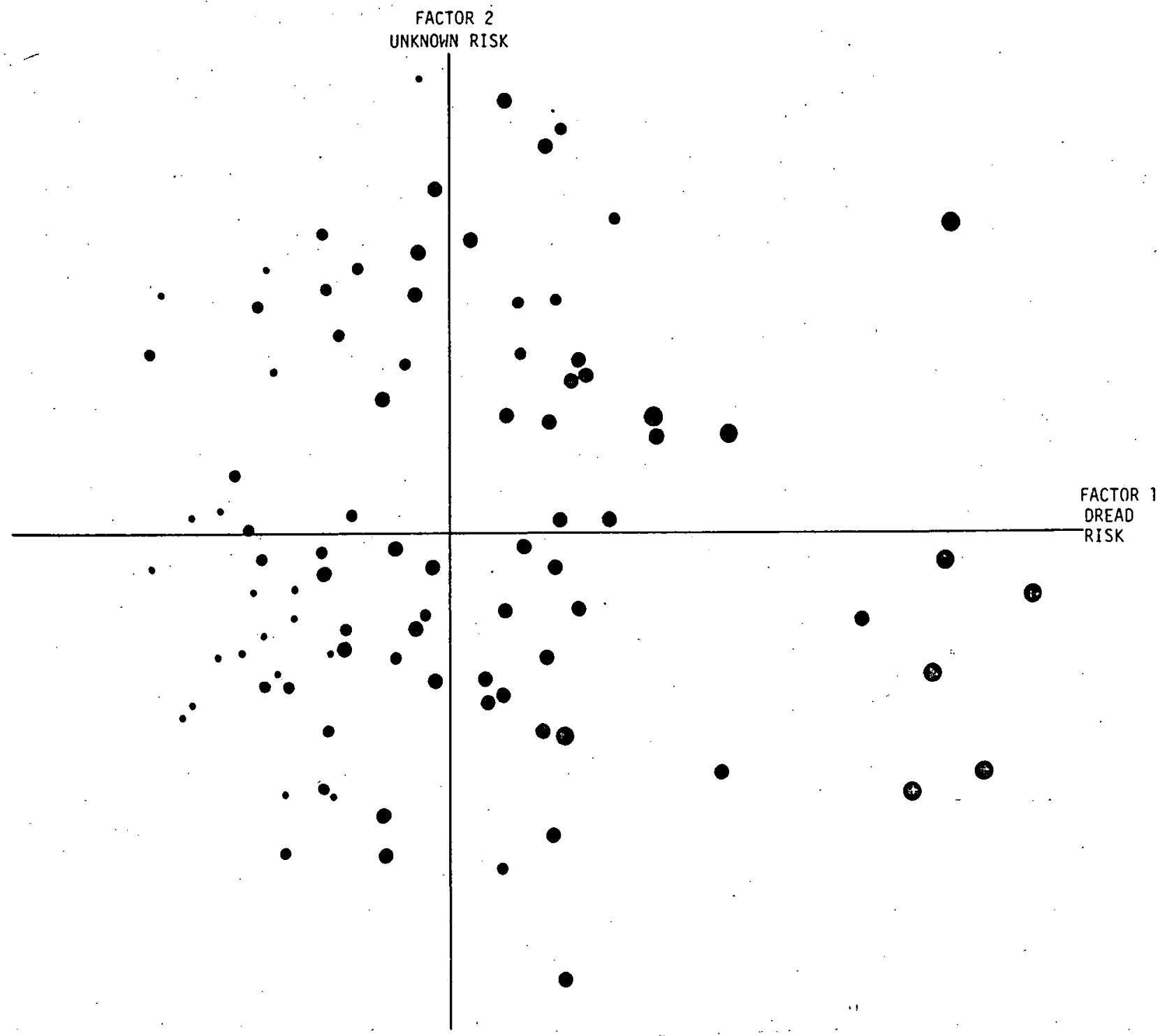

Figure 4. Attitudes towards regulation of the hazards shown in Figure 3. The larger the dot, the greater the desire for strict regulation to reduce risk. 


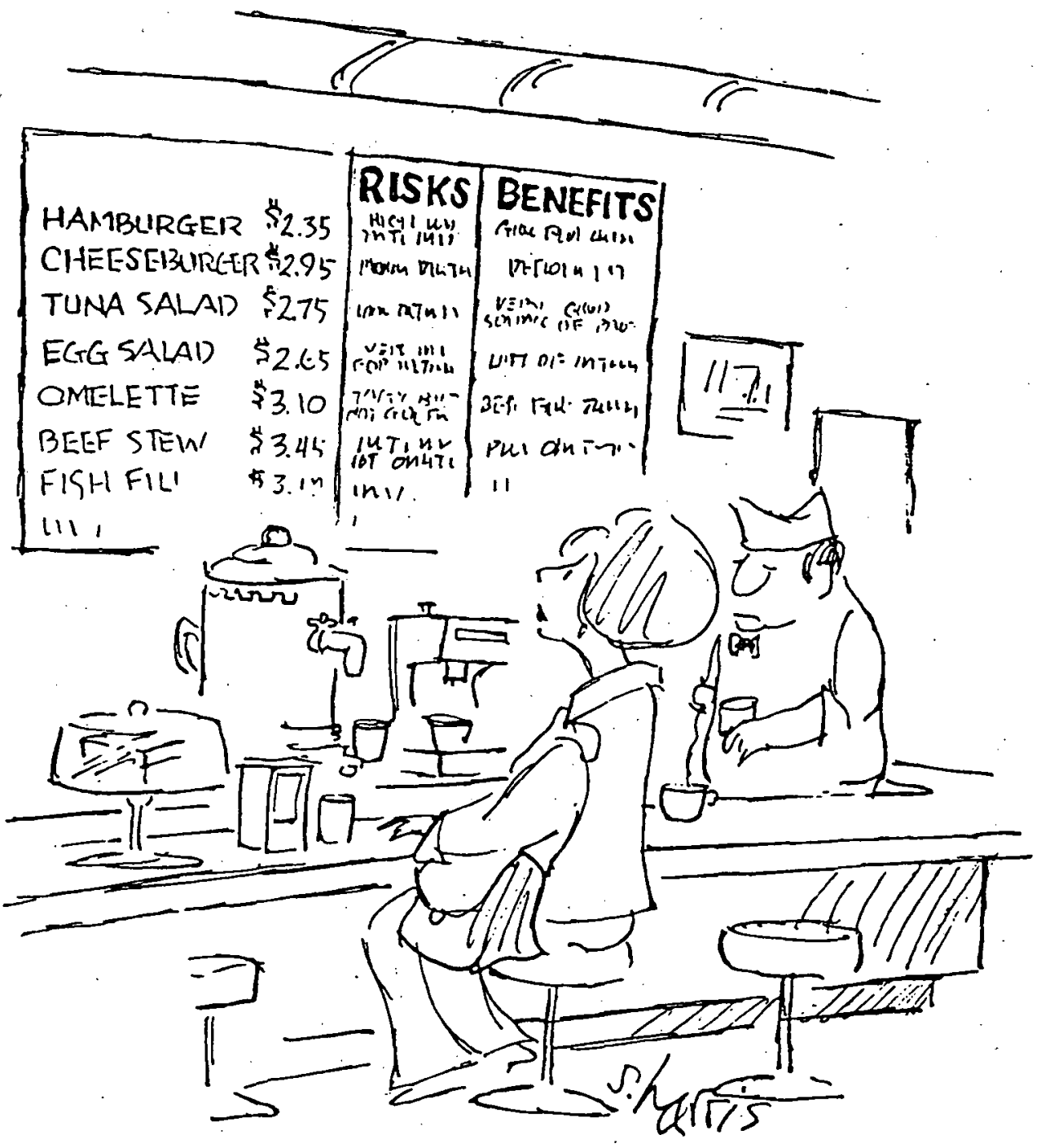

Figure 5. Drawing by S. Harris; (C) 1979

The New Yorker Magazine, Inc. 